\title{
Surgical closure of nasal septal perforation, early and long term observations*
}

\author{
Liv Kari Døsen ${ }^{1,2}$ and Rolf Haye $e^{1,2,3}$ \\ Department of Oto-rhino-laryngology, Lovisenberg Diakonale Hospital, 0440 Oslo, Norway \\ 2 Department of Oto-rhino-laryngology, Oslo University Hospital, 0027 Oslo, Norway \\ 3 Faculty of Medicine, University of Oslo, Oslo, Norway
}

SUMMARY Background: Results of surgical treatment of nasal septal perforation are usually evaluated using closure of the perforation as criterion of success. Patients, however, may still have symptoms.

Aim: To assess the long-term results of surgical treatment of nasal septal perforation with bilateral, posterior based mucoperichondrial septal flaps using a four-point symptom score to ultimately improve treatment and selection criteria.

Methodology: Patients were seen 6 months postoperatively. Questionnaires were sent to 116 surviving patients in 2008-2009. The response was 104. Patients reporting moderate or severe symptoms were seen as outpatients.

Results: Between 1987 and 2004, 126 patients were surgically treated using posterior based bilateral mucoperichondrial septal flaps. Sixteen patients had a reperforation during the first 3 months, and another 3 several years later. There was no correlation between early outcome and diagnosis, preoperative size of the perforation, gender or severity of preoperative crusting. There was an increased rate of reperforation with increasing age. Complications seen at the 6 months' follow-up of patients with closed perforations were lachrymal duct stenosis, partial vestibular stenosis, hypoesthesia, crusting and septal deviation, most of which were treatable. Long-term observation (mean of 10 years) of the same patients showed the following moderate or severe symptoms: crusting, obstruction and bleeding, mainly in men. Obstruction was often due to various forms of perennial rhinitis, sometimes to crusting and more rarely to septal deviation. Crusting was the only independent symptom. There was no correlation between crusting and diagnosis, preoperative size of the perforation, age or severity of preoperative crusting.

Conclusions: Results of the surgical technique using posterior based bilateral mucoperichondrial septal flaps for treatment of nasal septal perforations were good, but depend on surgical expertise and age of the patient. Long-term results from other studies will be a guide to choose the proper surgical procedure to minimize the number of late symptoms. Prosthetic treatment can be an alternative. Patients with return of symptoms should seek further advice.

Key words: otorhinolaryngological surgical procedure, nose, septum, perforation

\section{INTRODUCTION}

Nasal septal perforation (NSP) probably affects $0.9 \%$ of a population (1) and often causes distressing symptoms. Several surgical techniques have been proposed ${ }^{(2-4)}$ suggesting difficulty in obtaining optimal results. Although published results with bilateral, septal mucoperichondrial flap techniques ${ }^{(5-11)}$ often show a high closure rate, reports of long-term observation focus on the closure rate and not on the number of or severity of postoperative symptoms. The basis of the mucoperichondri- al flap technique is to close the NSP by sliding the septal mucoperichondrium above and below the NSP towards each other. We have used a modification of the bridge flap technique of Schulz-Coulon ${ }^{(5)}$ with the addition of bilateral transverse incisions along the nasal sill, which is one of the variants described by Watson and Barkdull (2).

The purpose of this study was to correlate the clinical data preoperatively, at 6 months and long term (minimum 4 years) 
to assess the success rate of both closure and symptom severity of this method, in an attempt to improve treatment and selection of patients.

\section{MATERIALS AND METHODS \\ Patients}

We have treated patients with symptomatic NSP since 1987 using bilateral, posterior based, septal mucoperichondrial flaps with an endonasal approach. Patients who opted for surgery instead of prosthesis have been included except for those with nasal neoplasia, cocaine abuse and Wegener's granulomatosis.

\section{Procedure}

We limited this procedure to small and medium sized perforations with a maximal vertical diameter of $15 \mathrm{~mm}$. The size of the NSP is recorded using the vertical diameter, as this dimension is the limit for this technique ${ }^{(5)}$. The horizontal dimension, however, is usually greater. The surgical approach is intranasal through a transfixion incision. The mucoperichondrium/periosteum is dissected from the septal cartilage and bone bilaterally, creating upper and lower tunnels, which are joined together. In so doing the nasopalatine nerves and arteries are necessarily divided. We have used the following modification, which makes the approximation of the flaps easier. The transfixion incision is extended laterally along the floor of the vestibulum at the nasal sill to the insertion of the inferior concha. Then the incision is carried posteriorly underneath the concha and curved medially to the middle of the floor of the nasal cavity (Figure 1) thus creating the lower flap that may be slid medially and cranially and at the same time rotated towards the midline. An upper flap is created by cutting the septal mucoperichondrium along the junction between the septum and the lateral cartilages as far as the posterior end of the NSP and then curved caudally (Figure 2) facilitating caudal sliding and rotation. In some cases when the perforation is small, no upper flap on the left side is required. Cartilage and/ or bone are harvested posterior to the perforation and brought forward into the perforation, thereby obtaining a three-layered closure. Additional aural cartilage was used in three patients. The flaps are approximated and sutured bilaterally with 5-0 vicryl. Silicone sheathings $(0.5 \mathrm{~mm})$ placed in both nasal cavities covering the septum, nasal floor and inferior concha maintain a moderate pressure on the mucoperichondrium. The sheathings are removed at one week. The operation is performed under general anaesthesia. Prophylactic antibiotics are given for one week. The patients are seen several times during the first two months. All of them are also examined six months postoperatively.

Clinical data such as etiology, symptoms, size and treatment of the NSP are registered consecutively at the time of treatment and postoperatively. The perforation is measured with a malleable probe.

\section{Questionnaires}

In 2008-2009, questionnaires were sent to all patients, except for six who had died and four without known address. In the questionnaire the patients were required to rate the following symptoms: whistling, crusting, bleeding and obstruction, on a four-point scale (none $=0$, mild $=1$, moderate $=2$ or severe $=$ 3 ) at a time when they did not have acute rhinitis. They should also rate their preoperative symptoms in the same manner. In addition they were asked about headache, chronic allergic rhinitis, chronic rhinosinusitis, their satisfaction with the operation, use of topical treatment and whether they had tried other treatment options. All patients reporting one or more moderate or severe symptoms were contacted in 2009. Most of them were seen by us, but a few by otolaryngologists at other hospitals and two contacted by telephone. The project was approved by the ethical committees of both hospitals.

\section{Statistics}

The statistics were performed with multivariate logistic regression with the dependent variables closed versus recurrent perforation at 6 months adjusted for diagnosis, preoperative size of the NSP, gender, age and preoperative crusting. For the late term results the dependent variables were no or mild versus moderate or severe crusting adjusted for the same variables. Unvariate logistic regression was used with the same dependant varibles to compare the individual diagnoses. Chi-square analysis was used for the results of the experience with the surgeon.

\section{RESULTS}

The senior surgeon has treated 126 patients with bilateral posterior based mucoperichondrial flaps between 1987 and mid 2004. Age and gender distribution is seen in Table 1. Septoplasty or rhinoseptoplasty was required in 66 patients in the same procedure. All patients were seen six months postoperatively. The results of the operation at six months in relation to the etiology are shown in Table 2. The reperforations appeared within the first postoperative three months. In the first five years of the study, eight of 17 operations resulted in reperforation, whereas only one of 42 in the last five years ( $p=$ 0.001). The response rate to the questionnaire was $89.7 \%$ (104 of 116). The median observation period was ten (4-21) years.

\section{Patients with successful closure}

\section{Short-term observation (6 months after surgery)}

The NSP remained closed after six months in 110 patients. Ninety-one $(82.7 \%)$ were completely satisfied and five $(4.5 \%)$ dissatisfied. The results of the operation in terms of closure were independent of diagnosis $(\mathrm{p}=0.307)$, size of the NSP $(\mathrm{p}=$ $0.598)$, gender $(p=0.117)$ or preoperative crusting $(p=0.532)$. There was increasing risk for reperforation with increasing age of the patient $(\mathrm{p}=0.024)$. We could not identify any significant difference in the results when comparing the individual diagnosis (Table 2). There were some complications and complaints, which are listed in Table 3. The cases with saddle deformity, lachrymal duct stenosis, vestibular partial stenosis and septal redeviation later underwent further treatment for the complication. 


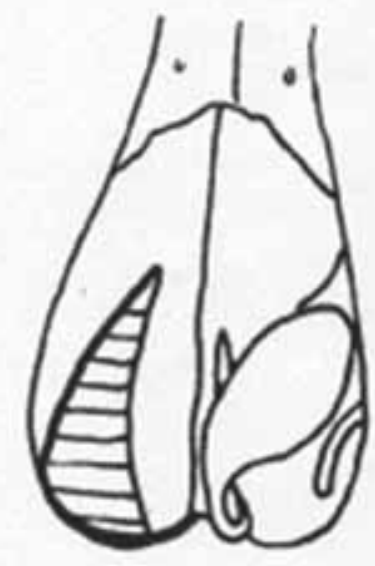

Figure 1. Oblique frontal view of the nose, looking directly at the right nasal floor. The incision is marked with a heavy line. Hatched area marks the dehiscence after medial mobilization (combined sliding and rotation) of the lower flap.

\section{Long-term follow up}

One patient with a reperforation was successfully reoperated upon and is therefore included in the long-term follow up. The results are therefore based on the response rate of $82.9 \%$ (92 of 111 operations). NSP had recurred in three patients after several years. Prolonged nasal picking was the cause in one patient and in another patient it reappeared during a severe unrelated illness when she had been treated with high doses of steroids for a prolonged period. These three reperforations were small and per se asymptomatic. The answers from these patients therefore are also included in the results. Sixty-six $(72.5 \%)$ of the responders were completely satisfied with the result and only two experienced deterioration of symptoms. One or more symptoms graded moderate or severe was reported by 41 patients. In one of them, it had only been temporary. All symptom scores for the remaining 40 patients are presented in Table 4. One patient reported that numbness in the premaxillary area was still present. The causes of nasal obstruction are shown in Table 5. Whistling and bleeding were associated with crusting. Crusting was the only independent symptom. The severity of this symptom was not related to either diagnosis $(p=0.632)$, size of the NSP $(p=0.803)$, age $(p=0.212)$, preoperative crusting $(p=0.163)$ or gender $(p=0.149)$. We could not find any significant difference in severity of crusting when comparing the individual diagnosis (Table 4). Thirtyfour patients had one or more symptoms graded two or more, excluding those with only chronic rhinitis. We could not find any correlation between severity of symptoms and diagnosis ( $p$ $=0.312)$, size of the NSP $(p=0.825)$, age $(p=0.493)$ or preoperative crusting $(\mathrm{p}=0.612)$. There was, however, an increased risk of severity of symptoms with male gender $(p=0.028)$.

\section{Patients with reperforation}

Short-term observation (6 months after surgery)

The NSP was found to be considerably reduced in size in all

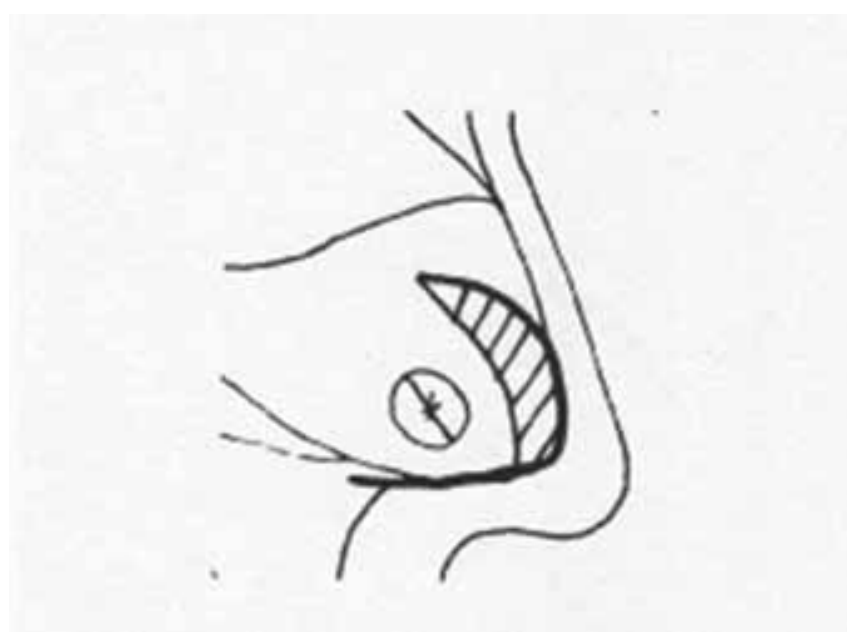

Figure 2. Lateral view of nasal septum. Incision is marked with a heavy line. Hatched area marks the resulting dehiscence after transposition (a combined sliding and rotation) of the upper flap.

but two of the 16 patients with reperforation. The vertical dimension of the recurred NSP was on average reduced from $8.3(3-15)$ to 2.9 (1-10) $\mathrm{mm}$. Nine patients had no or only mild symptoms. Correction of a septal deviation was performed at the time of surgery in five of them. The new perforation occurred at another location in three patients, one at the border of the membranous septum and two further posteriorly. The margins of the NSP were healed in seven of them.

\section{Long-term follow up}

Of the nine patients with no or mild symptoms, six were available for follow up. Their symptoms remained stable.

Of the seven patients with moderate or severe symptoms surgery had been successful in one and silicone button in two of them. Two of the others experienced increasing symptoms and were offered further surgical treatment.

\section{DISCUSSION}

The primary results of surgery using closure of the NSP as measure of success are satisfactory and in the same range as many studies using septal mucoperichondrial flaps ${ }^{(5-7)}$. Clinical studies, however, are never directly comparable ${ }^{(3)}$. Age and gender distribution of our surgically treated patients is the same as in our total series of 197 patients seen with NSP ${ }^{(12)}$. This is particularly important as we found an increased rate of reperforation with increase in age of the patient. There are some studies showing our gender distribution ${ }^{(9,10)}$ but this varies in other studies ${ }^{(5,8,11)}$. Size and frequency of causes of the NSP, and surgical modifications of technique also varies. The size of the NSP is often given as that of the largest diameter. For the surgical technique using posterior based mucoperichondrial septal flaps, the vertical diameter is the limiting factor as the flaps must be advanced in this direction ${ }^{(5)}$. Successful closure of larger perforations has been reported with other modifications of the technique. Such success may 
Table 1. Age and gender at the time of surgery

\begin{tabular}{lcccccc}
\hline Age & $16-19$ & $20-29$ & $30-39$ & $40-49$ & $50-59$ & 60 and more \\
\hline Male & 3 & 12 & 17 & 14 & 13 & 4 \\
Female & 4 & 13 & 18 & 11 & 15 & 2 \\
Total & 7 & 25 & 35 & 25 & 28 & 63 \\
\hline
\end{tabular}

Table 2. Primary results of surgery (6 months) related to cause of perforation $(n=126)$. Dependent variable perforated vs. non-perforated.

\begin{tabular}{lcccccccc}
\hline Cause & $\begin{array}{c}\text { Septal resec- } \\
\text { tion (Killian) }\end{array}$ & $\begin{array}{c}\text { Septo/septo- } \\
\text { rhinoplasty }\end{array}$ & Trauma & Cautery & Nose picking & Nasal sprays & Other & Total \\
\hline $\begin{array}{l}\text { Total } \\
(\%)\end{array}$ & 15 & 24 & 15 & 13 & 7 & 28 & 24 & 126 \\
& $(11,9)$ & $(19,0)$ & $(11,9)$ & $(10,3)$ & $(5,6)$ & $(22,2)$ & $(19,0)$ & $(100)$ \\
$\begin{array}{l}\text { Non-perforated } \\
(\%)\end{array}$ & 11 & 22 & 14 & 11 & 7 & 26 & 19 & 110 \\
$\begin{array}{l}\text { Reperforated } \\
(\%)\end{array}$ & $(8,7)$ & $(17,5)$ & $(11,1)$ & $(8,7)$ & $(5,6)$ & $(21,1)$ & $(15,1)$ & $(87,3)$ \\
P-value & $(3,2)$ & $(1,6)$ & $(0,8)$ & $(1,6)$ & $(0)$ & $(1,6)$ & $(4,0)$ & $(12,7)$ \\
& 0,072 & 0,222 & 0,512 & 0,684 & $*$ & 0,155 & 0,035 & \\
\hline
\end{tabular}

* Cannot calculate. Univariate logistic regression.

Table 3. Complications and complaints seen 6 months postoperatively in patients without perforation $(n=110)$.

\begin{tabular}{lc}
\hline Complications/complaints & No \\
\hline Epiphora & 2 \\
Saddle deformity & 2 \\
Partial vestibular stenosis| & 4 \\
Hypoesthesia & 2 \\
Moderate crusting & 5 \\
Septal deviation & 6 \\
Vasomotor rhinitis & 4 \\
\hline
\end{tabular}

in some instances perhaps be due to a more posterior location of the NSP as the mucoperichondrium is wider posteriorly. It is also possible that the size of the perforation was measured horizontally which is not limiting. Many of the NSPs of our patients had a greater horizontal diameter as also seen by Schulz-Coulon ${ }^{(5)}$. The importance of experience with the technique is suggested by the fact that closure was more frequently successful in the most recent five years of our study. NSPs caused by previous septal surgery particularly resection (Killian) were more common in the early period, and these cases are more difficult to manage surgically. This could, however, not be verified statistically, perhaps because the number of cases was small.

We encountered some complications, which were later success- fully treated. Lachrymal duct stenosis, which we have not seen reported before, was probably due to excessive undermining of the mucoperiostium beneath the inferior concha. This was done in an effort to gain sufficient width of the mucoperichondrial/periosteal flap. We have later not seen this complication as we have avoided the area near the ostium of the lachrymal duct during dissection. Partial stenosis of the floor of the vestibulum may be caused by the attempt to include some of the skin of the vestibulum in the lower flap to increase the length to cover the most anterior part of the NSP. The resulting lack of skin in the floor of the vestibulum may have led to stricture. This has later been avoided by limiting the incision to the nasal sill. The same complication has been recorded by SchulzCoulon ${ }^{(5)}$ and André et al., (11) who do not employ transverse incisions across the nasal sill. There may therefore be other explanations for this complication. Some surgeons have warned of saddle deformity caused by loss of cartilage underneath the nasal dorsum when upper flaps are used bilaterally to close the NSP ${ }^{(4,6)}$. A resultant saddle deformity occurred only twice. Although the procedure represents a potential hazard we do not believe that one should abstain from using upper flaps bilaterally when required. Temporary loss of sensitivity in the premaxillary area is not an infrequent consequence of the surgical procedure, which entails transsectioning of the nasopalatine nerves. Normally sensation returns within a few weeks or months. We have no explanation as to why it did not return completely in all patients, and we do not know how to avoid this complication, which has not been mentioned in other studies.

The long-term results were primarily based on questionnaires. 
Table 4. Long term follow up using crusting as the main criterion $(\mathrm{n}=92)$. Univariate logistic regression. Dependent variable moderate or severe crusting vs. no or mild crusting.

\begin{tabular}{|c|c|c|c|c|c|c|c|c|}
\hline Cause & $\begin{array}{l}\text { Septal resec- } \\
\text { tion (Killian) }\end{array}$ & $\begin{array}{l}\text { Septo/ } \\
\text { septo-rhino- } \\
\text { plasty }\end{array}$ & Trauma & Cautery & Nose picking & Nasal sprays & Other & Total \\
\hline $\begin{array}{l}\text { Total } \\
(\%)\end{array}$ & $\begin{array}{c}10 \\
(10,9)\end{array}$ & $\begin{array}{c}17 \\
(18,5)\end{array}$ & $\begin{array}{c}12 \\
(13,0)\end{array}$ & $\begin{array}{c}10 \\
(10,9)\end{array}$ & $\begin{array}{c}6 \\
(6,5)\end{array}$ & $\begin{array}{c}24 \\
(26,1)\end{array}$ & $\begin{array}{c}13 \\
(14,1)\end{array}$ & $\begin{array}{c}92 \\
(100)\end{array}$ \\
\hline $\begin{array}{l}\text { Crusting } \leqq 1 \\
(\%)\end{array}$ & $\begin{array}{c}8 \\
(8,7)\end{array}$ & $\begin{array}{c}14 \\
(15,2)\end{array}$ & $\begin{array}{c}8 \\
(8,7)\end{array}$ & $\begin{array}{c}10 \\
(10,9)\end{array}$ & $\begin{array}{c}3 \\
(3,3)\end{array}$ & $\begin{array}{c}20 \\
(21,7)\end{array}$ & $\begin{array}{c}8 \\
(8,7)\end{array}$ & $\begin{array}{c}71 \\
(77,2)\end{array}$ \\
\hline $\begin{array}{l}\text { Crusting } \geqq 2 \\
(\%)\end{array}$ & $\begin{array}{c}2 \\
(2,2)\end{array}$ & $\begin{array}{c}3 \\
(3,3)\end{array}$ & $\begin{array}{c}4 \\
(4,3)\end{array}$ & $\begin{array}{c}0 \\
(0)\end{array}$ & $\begin{array}{c}3 \\
(3,3)\end{array}$ & $\begin{array}{c}4 \\
(4,3)\end{array}$ & $\begin{array}{c}5 \\
(5,4)\end{array}$ & $\begin{array}{c}21 \\
(22,8)\end{array}$ \\
\hline p-value & 0,822 & 0,490 & 0,358 & $*$ & 0,122 & 0,406 & 0,156 & \\
\hline
\end{tabular}

* Cannot calculate

Table 5. Causes of obstruction graded moderate or severe by the patients $(n=31)$.

\begin{tabular}{cccccc}
\hline Septal deviation & Vestibular stenosis & Few objective findings & Perennial rhinitis & Crusting & Unknown \\
\hline 4 & 1 & 3 & 14 & 8 & 1 \\
\hline
\end{tabular}

The preoperative rating was retrospective, but it was correlated to the preoperative clinical data to minimize bias. Such rating may also be influenced by the regard of the patient for the surgeon. Although this may give rise to both milder and more exaggerated responses, we believe that it is easier to give a non-biased answer in a questionnaire than in a situation where the patient directly confronts the surgeon. Our findings in the patients who were recalled were usually in accordance with their prior reports, but in some cases somewhat exaggerated. We limited the scale of symptom grades to four categories to make it simpler for the patients. This grading scale has been assessed ${ }^{(13)}$ and successfully used by us ${ }^{(14)}$ and other authors in allergy ${ }^{(15)}$ and rhinology ${ }^{(16)}$.

The response rate in this study is high. It is, however, possible that results from the 19 patients not available for follow up or not answering the questionnaire might have biased the assessment. Five of them had symptoms at 6 months. Two patients were later surgically corrected; but two others with slight septal deviation were not treated. Hypoesthesia in the premaxillary area in one patient was still present after two years. We therefore believe that these patients' putative late term symptoms should not have altered the final assessment.

\section{Patients with successful closure}

It is difficult to compare the improvement in nasal symptoms to the few studies that have late term observation of more than one year. Neither the degree of the improvement nor of the individual symptoms have been specified ${ }^{(6,9,11)}$. One author has stated that all prior symptoms were completely reversed ${ }^{(10)}$. In some studies, the results are based upon hospital records or direct consultation between patient and their surgeon. Such reports may therefore be incomplete or biased. We hope that in the future there will be more long-term reports with specifying degree of symptoms. Many of our patients despite successful closure of their NSP still had moderate to severe symptoms that needed treatment. The cases with obstruction, however, were often due to various types of perennial rhinitis and not to the NSP or its treatment. We usually advise oral antihistamines and/or surgery to the inferior conchae as we believe topical steroids can cause perforation. Most of the other symptoms were due to or secondary to crusting. The question arises whether the crusting is due to the transverse incision along the nasal sill, which causes severance of the anterior blood supply to the mucoperichondrium. A few cases of crusting were seen during the first six months, but the majority of them occurred later when the blood supply is re-established. Schultz-Coulon (5) also noted that the mucous membrane was atrophic in some of his cases. We therefore assume that crusting is a foreseeable complication that may occur late after any surgical technique. We would, however, like to see more publications with late term results of other surgical procedures to clarify this.

All patients had been advised, but perhaps not adequately instructed how to use saline irrigation, oily sprays and ointments. Many patients have reported that local application of ointment was not effective and therefore had stopped using it. Only a few patients asked for a consultation when they answered the questionnaire. They only came forward on our invitation. Careful instruction in the application of an ointment containing fusidic acid once or twice daily for several months followed by an indifferent ointment has presently been 
temporarily successful in most of these patients. Oily solutions may sometimes be useful, but oil sprays were not favored by the patients. Crusting often recurs if the topical treatment is neglected particularly as in most of these cases the underlying mucosa is partially atrophic. Preoperative topical application of an antibiotic ointment may reduce crusting and improve the quality of the mucous membrane. This appears of limited value, as the results of surgery are independent of the preoperative severity of crusting. We cannot explain the male preponderance of those experiencing moderate or severe symptoms.

Prosthetic treatment is another option in cases with a straight septum. However, it is less often successful and crusting is common ${ }^{(14,16)}$. We have not been able to find criteria in choosing between prosthetic and surgical treatment.

\section{Patients with reperforation}

The NSPs were considerably reduced in size, six months postoperatively, in most of the patients with reperforation. This finding is in accordance with that of Schultz-Coulon ${ }^{(5)}$ and André et al. ${ }^{(11)}$. Some of the surgical failures were due to difficult dissection caused by previous septal surgery as we were not always able to mobilize the mucoperichondrium adequately. The remaining cartilage or bone used for transposition was sometimes inadequate, thin or brittle and probably should have been substituted with aural cartilage. The improvement in symptoms may be due to the recurrence of the NSP in an area where crusting does not take place such as the membranous septum or further posteriorly with less drying ${ }^{(4,17)}$. Some of the NSPs had well healed edges, which may explain the improvement ${ }^{(18)}$. Additionally, the septum was straightened during surgery in four cases, which thereby reduced obstruction and the size of the perforation. Crusting remained the least ameliorated symptom for some patients and may indicate that the mucosa is less healthy.

Our results indicate that patients with reperforation but without any or only mild symptoms at six months may not require further treatment. Patients with moderate or severe symptoms, however, should soon be considered for further treatment as their symptoms may otherwise deteriorate.

\section{ACKNOWLEDGEMENTS}

We thank dr. Robert Innes for help with the language and Mari Vårdal MSc (Oslo University Hospital) for help with the statistics.

\section{AUTHORSHIP CONTRIBUTION}

LKD has made the questionnaires, mailed, collected and compiled the questionnaires and the prior clinical data. $\mathrm{RH}$ has performed the surgery and registered the clinical data continuously. Both have prepared the manuscript and approved it.

\section{CONFLICT OF INTEREST}

No conflict of interest.

\section{REFERENCES}

1. Oberg D, Akerlund A, Johanson L, Bende M. Prevalence of nasal septal perforation: the Skövde population-based study. Rhinology. 2003; 41: 72-75.

2. Watson D, Barkdull G. Surgical Management of the Septal Perforation. Otolaryngol Clin N Am. 2009; 42: 483-493.

3. Goh AY, Hussain SS. Different surgical treatments for nasal septal perforation and their outcome. J Laryngol Otol. 2007; 121: 419-426.

4. Kridel RWH. Considerations in the etiology, treatment, and repair of septal perforations. Facial Plast Surg Clin North Am. 2004; 12: 435-450.

5. Schultz-Coulon HJ. Three-layered repair of nasoseptal defects. Arch Otolaryngol Head Neck Surg. 2005; 132: 213-217.

6. Fairbanks DNF. Closure of Nasal Septal Perforations. Arch Otolaryngol. 1980; 106: 509-513.

7. Goodman WS, Strelzow VV. The Surgical Closure of Nasoseptal Perforations. Laryngoscope. 1982; 92: 121-124.

8. Presutti L, Ciufelli MA, Marchiono D, Villari D, Marchetti A, Mattioli F. Nasal septal perforations: Our surgical technique. Arch Otolaryngol Head Neck Surg. 2007; 136: 369-372.

9. Pedrosa F. A Review of 25-Year Experience of Nasal Septal Perforation Repair. Arch Facial Plast Surg. 2007; 9: 12-18.

10. Ribeiro JS, Silva da GS. Technical Advances in the Correction of Septal Perforation Associated With Closed Rhinoplasty. Arch Facial Plast Surg. 2007; 9: 321-327.

11. André RF, Lohuis PJFM, Vuyk HD. Nasal septal perforation repair using differently designed, bilateral intranasal flaps, with nonopposing suture lines. J Plast Reconstr Aesteth Surg. 2006; 59: 829-834.

12. Døsen LK, Haye R. Nasal septal perforation 1981-2005: changes in etiology, gender and size. BMC Ear Nose Throat Disord. 2007; 7: $1-4$.

13. Lim M, Lew-Gor S, Darby Y, Brookes N, Scadding G, Lund VJ. The relationship between subjective assessment instruments in chronic rhinosinusitis. Rhinology. 2007; 45: 144-147.

14. Døsen LK, Haye R. Silicone button in nasal septal perforation. Long-term observations. Rhinology. 2008; 46: 324-327.

15. Scadding GK, Lund VJ, Jacques LA, Richards DH. A placebocontrolled study of fluticasone proprionate aqueous nasal spray and beclometasone diproprionate in perennial rhinitis: efficacy in allergic and non-allergic perennial rhinitis. Clin Exp Allergy 1995; 25: 737-743.

16. Luff DA, Kam IA, Williat DJ. Nasal septal buttons: Symptom scores and satisfaction. J Laryngol Otol. 2002; 116: 1001-1004.

17. Eng SP, Nilssen EL, Ranta M, White PS. Surgical management of septal perforation: an alternative to closure of the perforation. J Laryng Otol. 2001; 115: 194-197.

18. Cogswell LK, Goodacre TEE. The management of nasoseptal perforation. Br J Plast Surg. 2000; 53: 117-120.

Liv Kari Doesen
Dept. of Oto-rhino-laryngology
Lovisenberg Diakonale Hospital
0440 Oslo
Norway

Tel: $+47-23-225000$

Fax: +47-23-22 5646

E-mail: livd@1ds.no 